\title{
Promoção do Autoconceito e Auto Estima através de um Programa de Leitura a Par
}

\author{
Promoting Self-Concept and Self Esteem through a Peer Reading Program
}

\author{
Vera Monteiro* \\ Instituto Universitário de Lisboa, Lisboa, Portugal
}

\begin{abstract}
Resumo
Um autoconceito positivo é fundamental para o sucesso académico das crianças. Uma forma de promover o autoconceito é implementando programas tutoriais. Deste modo, esta investigação teve como objectivo implementar e avaliar os efeitos de um Programa de Leitura a Par, no autoconceito de alunos dos $2^{\circ}$ e $4^{\circ}$ anos de escolaridade e na auto-estima dos alunos mais velhos. Para avaliar as autopercepções utilizaramse duas escalas devido à discrepância de idade das crianças. Os resultados obtidos demonstram que este Programa teve um efeito positivo em todas as dimensões do autoconceito, quer para os tutores como para os tutorandos, e na auto-estima dos tutores. As crianças do Grupo Experimental apresentaram valores estatisticamente superiores aos dos alunos do Grupo de Controle.
\end{abstract}

Palavras-chave: Autoconceito, auto-estima, leitura, tutorado.

\begin{abstract}
A positive self-concept is essential for children's academic success. One way of promoting self-concept is by the implementation of tutorial programs. Thus, this research aimed to evaluate the effects of a Peer Reading Program on self-concept of $2^{\text {nd }}$ and $4^{\text {th }}$ grade students and on self-esteem of older students. In order to assess self-perceptions two scales were used due to the discrepancy in children's age. The results show that the Peer Reading Program had a positive effect on all dimensions of self-concept, for tutors and tutees, and on tutors' self-esteem. Children's outcomes obtained in the experimental group were statistically higher than those of students in the control group.

Keywords: Self-concept, self-esteem, reading, tutoring.
\end{abstract}

Nos últimos anos tem-se constatado através dos resultados de alguns estudos nacionais e internacionais sobre a aprendizagem da leitura (Departamento da Educação Básica [DEB], 2000; Inspecção Geral da Educação [IGE], 2001; Pinto-Ferreira, Serrão, \& Padinha, 2007; Sim-Sim, 2001) que as crianças portuguesas apresentam grandes dificuldades neste domínio e demonstram estar pouco motivadas para estas atividades. Nos estudos do PISA de 2000, 2003 e 2006, ao compararmos os alunos portugueses com os dos restantes países da OCDE, pôde-se constatar que os portugueses apresentam um desempenho em leitura abaixo do nível médio da OCDE, verificando-se, no entanto, uma ligeira tendência de recuperação dos resultados de 2000 para 2006 (Pinto-Ferreira et al., 2007). Desta forma, considera-se relevante uma intervenção no sentido de promover as competências de leitura nos alunos portugueses.

Contudo, para que a criança se torne num leitor eficaz, não é necessário apenas desenvolver competências efi-

"Endereço para correspondência: (ISPA-IU) Instituto Superior de Psicologia Aplicada - Instituto Universitário, Ciências Psicológicas, Sociais e da Vida. Rua Jardim do Tabaco, ${ }^{\circ}$ 34, Lisboa, Portugal 1149-041. E-mail: Vera.Martinho@ispa.pt. cazes em leitura, é também importante que ela sinta vontade de aprender (Gambrell \& Mazzoni, 1999). Dito de outro modo, na aprendizagem da leitura, para além das variáveis cognitivas, há que integrar as variáveis/os aspectos sociais, afetivos e motivacionais, para se compreender de uma forma mais clara o comportamento que a criança tem face à leitura. $\mathrm{O}$ insucesso em leitura pode, dessa forma, estar relacionado com alterações num(a) ou mais dessas variáveis/desses aspectos. Autores como Carneiro, Martinelli e Sisto (2003) afirmam que mudanças do tipo afetivo-emocionais, motivacionais e de relacionamento interpessoal podem contribuir para as dificuldades de aprendizagem. Consideram que em particular "o autoconceito vem sendo apontado como um dos influenciadores nesse processo devido à sua função na dinâmica da personalidade do indivíduo e de seu papel como um regulador dos estados afetivos e motivacionais do comportamento" (Carneiro et al., 2003, p. 428).

$\mathrm{O}$ autoconceito, na opinião de Marsh e Shavelson (1985), refere-se às autopercepções que o indivíduo vai formando através das suas experiências com o meio e as interpretações que faz dele. Estas são influenciadas principalmente pelas avaliações, reforços e atribuições do seu 
comportamento, feitas pelas pessoas que lhe são mais significativas. Para estes autores, o autoconceito é um constructo hipotético bastante útil na explicação e na predição dos comportamentos de uma pessoa. Segundo Cubero e Moreno (1995), as experiências de sucesso ou de fracasso escolar estimularão a forma como o aluno se autopercepciona. Esta autopercepção, que poderá ser positiva ou negativa, produzirá consequências na forma como a criança se envolve no processo de ensino-aprendizagem e no seu desempenho académico.

Se por um lado o autoconceito é visto como sendo um constructo que inclui aspectos cognitivos e comportamentais, a auto-estima, por seu turno, parece estar limitada a um componente avaliativo da área afectiva do self (Wigfield \& Karpathian, 1991), ou seja, o autoconceito é o conhecimento que o indivíduo tem acerca do self, por exemplo, "eu sou bom em leitura", ao passo que a autoestima é a forma como o indivíduo se sente acerca dos diferentes atributos do self, por exemplo, "eu estou contente da forma como sou".

A auto-estima para Harter (1993) baseia-se em processos afectivos como, por exemplo, os sentimentos positivos e negativos que um indivíduo tem sobre si próprio. A autora refere-se à auto-estima como a visão global que a pessoa tem de si própria. De acordo com Harter (1996), pode-se afirmar que autoconceito e autoestima são duas entidades psicológicas distintas. $\mathrm{O}$ autoconceito é um constructo multidimensional que se vai diferenciando cada vez mais com a idade. Por seu turno a auto-estima é unidimensional e só a partir dos oito anos é que as crianças conseguem fazer estes julgamentos globais enquanto pessoas.

Algumas investigações realizadas por Marsh e Craven (2006) têm sugerido que o autoconceito e o desempenho académico se reforçam mutuamente, e que cada um destes conceitos contribui para o aumento do outro. Um autoconceito e uma auto-estima positivos são muito importantes para uma aprendizagem eficaz (Leung, Marsh, \& Craven, 2005; Monteiro, 2003). Com o objectivo de analisarem a relação entre autoconceito e desempenho, Marsh, e Craven (2006) desenvolveram um modelo de efeitos recíprocos em que consideram que existe uma relação causal dinâmica e recíproca entre estes dois constructos. Desta forma a promoção do auto-conceito académico conduzirá a um melhor desempenho mas, a promoção do desempenho académico também conduzirá a um autoconceito mais positivo. Em termos educacionais e de acordo com os autores deste modelo, os professores deveriam implementar programas que promovessem simultaneamente o autoconceito académico e o desempenho.

Baseados nesta sugestão resolvemos criar e implementar um programa tutorial em leitura que levasse à promoção do autoconceito e auto-estima das crianças que nele participassem, bem como à promoção do desempenho em leitura. Neste artigo iremos, no entanto, referir apenas os resultados obtidos em termos de autoconceito. Tendo em conta que a literatura refere que é possível especificar que o processo tutorial desenvolve na criança sentimentos de autoconfiança, consideramos que este método poderá ser utilizado em contexto de sala de aula na promoção de valores de autoconceito e auto-estima mais positivos. $\mathrm{Na}$ verdade, certos alunos que experimentaram no seu percurso escolar o sentimento de fracasso, interiorizando a imagem de mau aluno, conseguem numa relação tutorial superar esse sentimento, na medida em que sentem convergir à sua volta o respeito e a admiração dos seus colegas. Essa nova forma do aluno se ver tem influência decisiva na orientação da sua capacidade relacional socio-afetiva mas, ao mesmo tempo, ajuda a desenvolver as suas competências de aprendizagem de nível estritamente académico e resulta, na maior parte das vezes, numa elevação do seu autoconceito geral (Monteiro, 2003; Rumbaugh \& Brown, 2000).

A situação tutorial entre pares caracteriza-se pela ajuda que um sujeito mais competente (tutor) fornece a um colega menos competente (tutorando) na realização de uma tarefa que este último não consegue resolver sozinho (Monteiro, 2003). Este tipo de interação caracteriza-se por uma atribuição de papéis específicos a cada um dos elementos da díade (Topping \& Brice, 2004). A investigação que tem sido feita para analisar o efeito de programas tutoriais no autoconceito e auto-estima de crianças e jovens é muito escassa. No entanto, os estudos realizados vieram a revelar os efeitos positivos da aplicação do método tutorial, indicando que o processo tutorial desenvolve na criança sentimentos de auto-confiança e promove o autoconceito (Duran \& Monereo, 2008; Leung et al., 2005; Miller \& Moran, 2006; Monteiro, 2003; Rohrbeck, Ginsburg-Block, Fantuzzo, \& Miller, 2003; Rumbaugh \& Brown, 2000; Topping, \& Brice, 2004; Veerkamp, \& Kamps, 2007).

Com base na revisão da literatura apresentada anteriormente, este estudo tem como objectivo investigar qual o impacto que um Programa de Leitura a Par pode ter no autoconceito e auto-estima das crianças que nele participem. Deste modo foram levantadas as seguintes hipóteses:

1. Esperamos que tutores $\left(4^{\circ}\right.$ ano $)$ e tutorandos $\left(2^{\circ}\right.$ ano $)$ apresentem valores de autoconceito significativamente superiores aos dos colegas do Grupo de Controle, que não participaram no Programa de Leitura a Par.

2. Os alunos do $4^{\circ}$ ano que participarem no Programa apresentarão valores de auto-estima significativamente superiores aos dos seus colegas do Grupo de Controle.

\section{Método}

Neste estudo optou-se por um desenho quase experimental com a finalidade de comparar os resultados dos alunos que participaram no Programa de Leitura a Par 
(Grupo Experimental) com os dos alunos que não participaram (Grupo de Controle). Este estudo seguiu a estrutura clássica de investigação: pré-teste, tratamento experimental e pós-teste. Na situação de pré-teste e pós-teste todas as crianças foram avaliadas individualmente, no que se refere aos seus valores de autoconceito $\left(2^{\circ}\right.$ e $4^{\circ}$ anos $)$ e auto-estima ( $4^{\circ}$ ano). Na fase experimental, os alunos do Grupo Experimental participaram de um Programa de Leitura a Par enquanto os alunos do Grupo de Controle fizeram atividades de leitura individualmente.

\section{Participantes}

Nesta investigação participaram 160 crianças com idades compreendidas entre os 7 e os 12 anos de idade. Oitenta destas crianças frequentavam o $2^{\circ}$ ano de escolaridade e as outras 80 do $4^{\circ}$ ano. Formaram-se assim dois grupos: o Grupo de Controle e o Grupo Experimental constituídos por 40 crianças do $2^{\circ}$ ano e 40 crianças do $4^{\circ}$ ano de escolaridade.

\section{Selecção dos Participantes}

No início da investigação pediu-se aos professores de todos os alunos do $2^{\circ} \mathrm{e} 4^{\circ}$ anos de escolaridade das escolas que participaram no estudo que avaliassem os seus alunos em leitura. Começou-se por explicar que existem três conceitos básicos para fazer essa avaliação: fluência, correção e compreensão em leitura. Após a explicitação dos conceitos pediu-se aos docentes que preenchessem um questionário com a seguinte questão: Como avalia o ... (nome do aluno) em leitura tendo em conta o seu desempenho em termos de fluência, correção e compreensão? A resposta foi dada numa escala de tipo Likert de sete pontos, em que 1 correspondia a um fraco desempenho em leitura e 7 a um excelente desempenho em leitura.

Para a nossa investigação foram selecionadas todas as crianças que obtiveram valores iguais ou inferiores a três. Em seguida, de forma aleatória, metade dos alunos foram distribuídos para o Grupo Experimental e outra metade para o Grupo de Controle. Posteriormente, as crianças do Grupo Experimental foram agrupadas em díades, compostas por uma criança do $2^{\circ}$ ano e outra do $4^{\circ}$ ano de escolaridade, aleatoriamente.

\section{Programa de Leitura a Par}

Ao concebermos o Programa de Leitura a Par implementado nesta investigação, houve uma grande preocupação em introduzir algumas das orientações teóricas em que se fundamentam as abordagens socioconstrutivistas. Houve, ainda, o cuidado de, a partir das abordagens teóricas sobre a motivação, autoconceito, aprendizagem e desenvolvimento da leitura, introduzir no programa alguns aspectos que, de acordo com os autores, são importantes na promoção da motivação para a leitura, do autoconceito e no desenvolvimento de competências em leitura.

\section{Método Tutorial}

Nesta investigação utilizou-se o método tutorial, em que alunos mais competentes em leitura ( $4^{\circ}$ ano) ajudaram um colega menos competente $\left(2^{\circ}\right.$ ano) em tarefas de leitura. O nosso programa decorreu no período letivo, durante oito semanas consecutivas. Realizavam-se três sessões semanais, com a duração máxima de 30 minutos por sessão.

\section{Materiais}

Foram disponibilizados livros de literatura infantil, livros de receitas, revistas variadas, jornais, histórias em cassetes audio acompanhadas do respectivo texto escrito, canções (cassete-áudio e poema). Foram constituídos dossiers com uma enorme variedade e diversidade de materiais de leitura. A apresentação dos materiais foi sendo renovada e atualizada semanalmente, de modo a que o interesse e a curiosidade em explorá-los fossem mantidos ao longo de todo o programa.

\section{Preparação dos Tutores}

Antes do programa começar fizeram-se duas reuniões com os tutores individualmente e uma com os tutores e tutorandos onde foram discutidos os objectivos do Programa e os procedimentos a utilizar. Não foi dado qualquer treino aos tutores. Foram definidos os objectivos gerais para tutores e tutorandos bem como os papeis que cada um iria assumir durante as sessões tutoriais. Foram dadas algumas orientações aos tutores sobre a forma como poderiam fazer a planificação das sessões tutoriais e foram ainda discutidas algumas características sobre os materiais que iriam ser utilizados.

\section{Suporte e Monitorização}

Durante as sessões tutoriais o investigador responsável pelo programa supervisionou a forma como o programa estava sendo implementado. Observou as díades e a forma como interagiam de forma a resolver algum problema ou dificuldade, providenciando ajuda sempre que necessário.

\section{Procedimentos Utilizados no Programa de Leitura a Par}

Durante as sessões tutoriais, tutor e tutorando podiam escolher as tarefas que mais lhes interessavam. Este procedimento foi feito alternadamente, ou seja, uma vez escolhia o tutor a tarefa de leitura, na vez seguinte era o tutorando e assim sucessivamente. A leitura podia ser feita em voz alta ou silenciosamente. Tutor e tutorando, no início de cada actividade de leitura decidiam se a leitura em voz alta iria ser feita individualmente ou se iria ser feita pelos dois em simultâneo ou, ainda, se apenas uma parte era feita individualmente e outra parte pelos dois. $\mathrm{O}$ tutor devia intervir sempre que o colega cometia um erro ou hesitva na leitura de uma palavra. Cabia ao tutor decidir qual ou quais os procedimentos de correcção que lhe pareciam ser mais eficazes à situação em causa. O refor- 
ço positivo devia ser utilizado com bastante regularidade pelo tutor, sempre que a leitura era feita de forma correta e sempre que o tutorando ultrapassasse uma dificuldade sentida anteriormente. Este reforço era um feedback positivo relativo à realização do tutorando e deveria conter informação sobre a tarefa. Deveria ser contingente ao esforço no sentido de promover uma percepção de competência mais positiva.

A discussão do texto, no final da leitura, e o levantamento de uma questão, por cada um dos elementos da díade, era uma das partes essenciais do método para que, desta forma ambos tivessem uma melhor compreensão do texto lido.

\section{Instrumentos}

Devido à discrepância de idades dos participantes e às grandes dificuldades em leitura manifestadas pelas crianças do $2^{\circ}$ ano de escolaridade, foram utilizadas duas escalas para avaliar as autopercepções dos alunos. Para avaliar o Autoconceito dos alunos do $2^{\circ}$ ano de escolaridade foi utilizada uma adaptação feita por Mata, Monteiro, Peixoto, e Alves-Martins (1998) da Escala Pictórica da Percepção de Competência e Aceitação Social para Crianças de Harter e Pike (1983). Esta escala é constituída por quatro dimensões diferentes: Competência Cognitiva, Competência Física, Aceitação entre Pares e Aceitação Materna, agrupados numa estrutura de dois fatores que representam a Competência Geral (que inclui as dimensões Competência Cognitiva e Competência Física [seis itens cada]) e a Aceitação Social (que inclui as dimensões Aceitação entre Pares [quatro itens] e Aceitação Materna [oito itens]). A escala é assim constituída por um total de vinte e quatro itens. Cada item é apresentado às crianças sob a forma de uma imagem. O formato dos itens permite uma dupla opção. Por um lado, a criança terá de escolher entre duas descrições de sujeitos, aquela com que se identifica mais. Por outro lado, a criança terá de exprimir o seu grau de identificação ("Tal e qual assim" ou "Um bocadinho assim"). As opções da criança são avaliadas de 1 a 4, indicando este último valor uma alta competência percebida e o valor 1 uma baixa competência percebida. Posteriormente, somam-se as pontuações dos itens de cada dimensão dividindo-se em seguida o total pelo número de itens, de modo a obter-se a média de cada subescala.

$\mathrm{O}$ instrumento utilizado para avaliar o autoconceito e a auto-estima das crianças do $4^{\circ}$ ano de escolaridade foi Self-perception Profile for Children, de Harter (1985) adaptado por Alves-Martins, Peixoto, Mata, e Monteiro (1995), para a população portuguesa. A escala avalia cinco domínios específicos do autoconceito: Aceitação Social, Competência Escolar, Competência Atlética, Aparência Física e Comportamento e um domínio mais geral: a Auto-Estima. A escala contém trinta e seis itens referentes às seis dimensões. $\mathrm{O}$ formato dos itens que compõem a escala, tal como a anterior, permitem uma dupla opção. Por um lado, a criança terá de escolher entre duas descrições de crianças, aquela com que se identifica mais. Por outro lado, a criança terá de exprimir o seu grau de identificação ("Tal e qual assim" ou "Um bocadinho assim"). A cotação e interpretação são idênticas à da escala anterior.

\section{Análise de Dados}

Para analisar o efeito da implementação do Programa de Leitura a Par na promoção do autoconceito e autoestima nas crianças do $2^{\circ}$ e $4^{\circ}$ ano de escolaridade, os dados foram, num primeiro momento, analisados de forma descritiva e, num segundo momento foram apresentados os resultados das comparações efetuadas as médias dos grupos em estudo. Quanto aos procedimentos estatísticos optou-se pelo teste de análise de variância de medições repetidas (ANOVA) que permite comparar médias a partir de amostras emparelhadas. Possibilita também o controle de fontes de variabilidade, que podendo não ter nada a ver com o tratamento, poderão, de algum modo, mascarar o efeito deste, nomeadamente os valores médios iniciais dos grupos utilizados no estudo. Dessa forma, é possível controlar as diferenças iniciais entre os indivíduos (Maroco, 2007). Os pressupostos do método, nomeadamente a distribuição normal e a homogeneidade de variâncias foram avaliados, respectivamente com o teste Kolmogorov-Smirnov e com o teste Levene, constatando-se que para algumas dimensões do autoconceito estes pressupostos foram encontrados mas, para outras não. No entanto devido à dimensão da amostra e ao fato do número de sujeitos em cada grupo ser semelhante, Maroco (2007) considera que, nestas situações, a estatística paramétrica se mostra robusta para ultrapassar esses problemas.

\section{Resultados}

\section{Resultados Obtidos pelos Alunos do $2^{\circ}$ Ano de Escolaridade}

A análise descritiva das médias apresentadas na Tabela 1 sugere que as crianças do Grupo de Controle (GC) fizeram ligeiros progressos do pré para o pós-teste, nas diferentes dimensões do autoconceito. Observa-se que é nas dimensões referentes ao fator Aceitação Social que se dá uma maior evolução.

Ao analisarmos as médias dos alunos do Grupo Experimental podemos constatar que estes registaram uma maior evolução, do primeiro para o segundo momento avaliativo, do que as crianças do Grupo Controle, constatando-se que as médias no segundo momento avaliativo são bastante elevadas e muito próximas do nível máximo (4) para as crianças do Grupo Experimental, em particular na Aceitação entre Pares e na Competência Cognitiva. No conjunto das quatro dimensões de autopercepção, foi na dimensão da Aceitação Materna que estas crianças apresentaram valores de autopercepção mais baixos. 
Monteiro, V. (2012). Promoção do Autoconceito e Auto Estima através de um Programa de Leitura a Par.

Tabela1

Médias e DP nas Dimensões do Autoconceito Observados nos Dois Grupos de crianças do $2^{\circ}$ Ano de Escolaridade em cada um dos Momentos Avaliativos

\begin{tabular}{|c|c|c|c|c|c|c|c|c|c|c|}
\hline \multirow{3}{*}{ Dimensões/Factores } & \multicolumn{5}{|c|}{ Grupo Experimental } & \multicolumn{5}{|c|}{ Grupo de Controle } \\
\hline & \multicolumn{2}{|c|}{ Pré-Teste } & \multicolumn{2}{|c|}{ Pós-Teste } & \multirow{2}{*}{$\begin{array}{l}\text { Evolução } \\
\text { (Pós-Pré) }\end{array}$} & \multicolumn{2}{|c|}{ Pré-Teste } & \multicolumn{2}{|c|}{ Pós-Teste } & \multirow{2}{*}{$\begin{array}{l}\text { Evolução } \\
\text { (Pós-Pré) }\end{array}$} \\
\hline & $M$ & $D P$ & $M$ & $D P$ & & $M$ & $D P$ & $M$ & $D P$ & \\
\hline Competência Cognitiva & 3,292 & 0,355 & 3,888 & 0,157 & 0,596 & 3,167 & 0,403 & 3,241 & 0,372 & 0,074 \\
\hline Competência Física & 3,196 & 0,462 & 3,667 & 0,233 & 0,471 & 3,012 & 0,518 & 3,083 & 0,417 & 0,071 \\
\hline Competência Geral & 3,244 & 0,312 & 3,777 & 0,135 & 0,533 & 3,099 & 0,348 & 3,163 & 0,297 & 0,063 \\
\hline Aceitação Materna & 2,959 & 0,662 & 3,263 & 0,405 & 0,304 & 2,781 & 0,607 & 2,913 & 0,518 & 0,132 \\
\hline Aceitação Entre Pares & 3,143 & 0,609 & 3,794 & 0,282 & 0,651 & 3,044 & 0,755 & 3,194 & 0,621 & 0,150 \\
\hline Aceitação Social & 3,052 & 0,542 & 3,528 & 0,287 & 0,476 & 2,913 & 0,616 & 3,053 & 0,524 & 0,140 \\
\hline
\end{tabular}

Ao examinarmos os resultados da análise de variância constatamos que as evidências que apontamos anteriormente se confirmaram. Relativamente à evolução dos valores das autopercepções avaliados, observaram-se diferenças estatisticamente significativas entre os dois momentos em todas as dimensões avaliadas: Competência Cognitiva $(F=178,387 ; p<0,001$; Potência $=1.000)$, Competência Física $(F=88,804 ; p<0,001$; Potência $=1.000)$, Competência Geral, $(F=224,374 ; p<0,001$; Potência $=1.000)$ Aceitação Materna $(F=47,133 ; p<0,001$; Potência $=1.000)$, Aceitação entre Pares $(F=129,662$; $p<0,001$; Potência $=1.000)$ e Aceitação Social $(F=$ 121,614; $p<0,001$; Potência=1.000). Considerando as crianças dos dois grupos, os valores de autopercepção foram mais elevados no $2^{\circ}$ momento avaliativo do que no $1^{\circ}$ momento. Finalmente, verificou-se que o efeito do Programa de Leitura a Par sobre as autopercepções das crianças depende do grupo de crianças (Experimental vs Controle), quer nos factores gerais quer nas dimensões específicas da autopercepção, como demonstra a interação significativa na percepção de Competência Cognitiva $(F=107,53 ; p<0,001 ;$ Potência $=1.000)$, Competência Física $(F=48,43 ; p<0,001$; Potência $=1.000)$, na Competência Geral $(F=129,41 ; p<0,001$; Potência $=1.000)$, na Aceitação Materna $(F=7,38 ; p=0,008$; Potência $=1.000)$, na Aceitação entre Pares $(F=50,65 ; p<0,001$; Potência $=1.000)$ e na Aceitação Social $(F=36,03 ; p<0,001$; Potência $=1.000$ ). Como se pode verificar na Tabela 1 , os valores de autopercepção são mais pronunciados nas crianças do Grupo Experimental no $2^{\circ}$ momento avaliativo. Estes resultados revelam que o Programa de Leitura a Par teve um efeito positivo nos valores de autopercepção das crianças que nele participaram.

\section{Resultados Obtidos pelos Alunos do $4^{\circ}$ Ano} de Escolaridade

A Tabela 2 apresenta o padrão evolutivo do pré para o pós-teste dos dois grupos em estudo (experimental vs controle).

Tabela 2

Médias e DP nas Dimensões do Autoconceito Observados nos Dois Grupos de crianças do $4^{\circ}$ Ano de Escolaridade em cada um dos Momentos Avaliativos

\begin{tabular}{|c|c|c|c|c|c|c|c|c|c|c|}
\hline \multirow{3}{*}{ Dimensões/Factores } & \multicolumn{5}{|c|}{ Grupo Experimental } & \multicolumn{5}{|c|}{ Grupo de Controle } \\
\hline & \multicolumn{2}{|c|}{ Pré-Teste } & \multicolumn{2}{|c|}{ Pós-Teste } & \multirow{2}{*}{$\begin{array}{l}\text { Evolução } \\
\text { (Pós-Pré) }\end{array}$} & \multicolumn{2}{|c|}{ Pré-Teste } & \multicolumn{2}{|c|}{ Pós-Teste } & \multirow{2}{*}{$\begin{array}{l}\text { Evolução } \\
\text { (Pós-Pré) }\end{array}$} \\
\hline & $M$ & $D P$ & $M$ & $D P$ & & $M$ & $D P$ & $M$ & $D P$ & \\
\hline Competência Escolar & 2,667 & 0,471 & 3,438 & 0,235 & 0,771 & 2,546 & 0,532 & 2,708 & 0,069 & 0,162 \\
\hline Aceitação Social & 2,930 & 0,311 & 3,496 & 0,144 & 0,566 & 2,90 & 0,360 & 3,067 & 0,366 & 0,167 \\
\hline Competência Atlética & 2,683 & 0,420 & 3,06 & 0,332 & 0,377 & 2,641 & 0,301 & 2,746 & 0,277 & 0,105 \\
\hline Aparência Física & 3,037 & 0,615 & 3,533 & 0,350 & 0,496 & 3,008 & 0,557 & 3,108 & 0,462 & 0,1 \\
\hline Comportamento & 3,013 & 0,498 & 3,762 & 0,202 & 0,749 & 2,954 & 0,622 & 3,025 & 0,538 & 0,071 \\
\hline Auto-Estima & 3,150 & 0,493 & 3,692 & 0,243 & 0,542 & 3,129 & 0,498 & 3,275 & 0,395 & 0,146 \\
\hline
\end{tabular}

Verifica-se nos dados obtidos pelo Grupo de Controle que há um ligeiro aumento dos valores médios do pré para o pós-teste, ao passo que as crianças que participaram no Programa de Leitura a Par apresentam valores 
médios nestas cinco dimensões específicas e na situação de pós-teste muito superiores aos do primeiro momento de avaliação. É ainda possível constatar que é nas dimensões da Competência Escolar e Comportamento, onde se verifica a maior evolução nas crianças que participaram no Programa de Leitura a Par. Quanto aos valores médios de Auto-Estima, regista-se uma grande evolução do pré para o pós-teste para as crianças que participaram no Programa de Leitura a Par $(0,542)$, que contrasta com a reduzida evolução dos valores médios das crianças do grupo de controle $(0,146)$.

Os resultados da análise de variância para a evolução dos valores de autoconceito nas cinco dimensões avaliadas e para a auto-estima revelaram a existência de diferenças estatisticamente significativas: Competência Escolar $(F=280,594 ; p<0,001$; Potência $=1.000)$, Comportamento $(F=155,220 ; p<0,001$; Potência $=1.000)$, Competência Atlética $(F=159,436 ; p<0,001$; Potência $=1.000)$, Aparência Física $(F=103,533 ; p<0,001$; Potência $=1.000)$, Aceitação Social $(F=297,260 ; p<0,001$; Potência $=1.000)$ e Auto-estima ( $F=134,147 ; p<0,001)$. Tendo em conta as crianças dos dois grupos, e como se pode observar na Tabela 2, os valores de autopercepção foram mais elevados no segundo momento de avaliação. Relativamente ao efeito do Programa de Leitura a Par sobre o autoconceito e auto-estima das crianças, este revela-se estatisticamente significativo como demonstra a interacção nas dimensões: Competência Escolar $(F=119,203 ; p<0,001$; Potência $=1.000)$, Comportamento $(F=106,27 ; p<0,001$; Potência $=1.000)$, Competência Atlética $(F=50,94$; $p<0,001$; Potência $=1.000)$, Aparência Física $(F=45,70$; $p<0,001$; Potência $=1.000)$, Aceitação Social $(F=88,44$; $p<0,001$; Potência $=1.000)$ e Auto-estima $(F=44,47$; $p<0,001$; Potência $=1.000)$. Podemos, deste modo, afirmar que a implementação do Programa de Leitura a Par teve um efeito positivo nos valores de autoconceito e autoestima das crianças que dele participaram.

\section{Discussão}

A nossa preocupação principal nesta investigação foi observar e analisar a existência de mudanças nos valores de autoconceito e auto-estima em crianças do $1^{\circ}$ ciclo de escolaridade, que participaram num Programa de Leitura a Par.

Quanto às crianças do $2^{\circ}$ ano, o Programa teve um efeito de tal forma positivo nas suas auto percepções que o seu efeito se generalizou às dimensões mais específicas do autoconceito, nomeadamente na percepção de Competência Cognitiva e Física e, ainda, na percepção da Aceitação Materna e Aceitação de Pares. A análise dos dados mostra que os efeitos foram, no entanto, mais positivos na Aceitação entre Pares e na percepção da Competência Cognitiva, sendo estes efeitos menos positivos na Aceitação Materna. Estes dados permitem-nos colocar em evidência a natureza multidimensional do autoconceito corroborando resultados de vários estudos anteriores (Harter, 1999; Marsh \& Hattie, 1996; Marsh \& O’Mara, 2008).

A interacção estabelecida entre crianças que participaram no Programa de Leitura a Par desencadeou algumas mudanças na sua autopercepção de competência. Segundo Good e Brophy (2002), o autoconceito de competência desenvolve-se a partir de dois aspectos importantes. Por um lado, a partir de fontes de informação interna, ou seja, das avaliações feitas pelos próprios sujeitos, dos efeitos das suas acções. Por outro lado, desenvolve-se a partir de fontes externas de informação, ou seja, das avaliações feitas por outras pessoas consideradas mais significativas. Desse modo, as crianças do $2^{\circ}$ ano que participaram no Programa de Leitura a Par sentiram que tinham feito progressos em leitura, ao trabalharem com a ajuda de um colega mais competente, que elogiava o seu trabalho frequentemente. $\mathrm{O}$ facto das médias em termos de Competência Cognitiva serem superiores à maioria das restantes médias das outras dimensões parece plausível, uma vez que, segundo Harter (1999), os julgamentos que as crianças fazem acerca das suas competências estão mais intimamente relacionadas com as avaliações que fazem do self, sendo as restantes dimensões mais influenciadas com o que as crianças acham que os outros pensam delas. Segundo a autora, existe uma interferência do self ideal sobre $o$ self real nestas idades, o que leva a que os resultados em competência apareçam inflacionados.

Segundo Harter (1999), o autoconceito é um constructo socialmente estabelecido, que representa em grande parte a internalização das atitudes, que os outros mais significativos têm sobre nós. A Aceitação Social refere-se ao modo como a pessoa percebe a forma como os outros gostam dela e a admiram. Para Harter e Pike (1983), os itens que avaliam a Aceitação Social, nomeadamente a Aceitação entre Pares e a Aceitação Materna vão avaliar o grau em que a criança se sente compreendida/integrada pelos seus pares, se se sente popular e de que modo os outros gostam dela. Acrescentam que estes itens são bons indicadores da qualidade e da intensidade das relações estabelecidas pelas crianças. A partir dos dados obtidos no nosso estudo, percebemos que, embora a relação que as crianças têm com a suas mães seja percebida como positiva, ela é menos positiva do que a percepção que eles têm da relação que estabeleceram com os seus colegas, ou seja, estas crianças, em geral, consideram que têm uma relação mais positiva com os seus colegas do que com as suas mães.

Constatamos, no entanto, que o Programa de Leitura a Par teve um efeito positivo e significativo na dimensão da Aceitação Materna, embora discreto. Pensamos que estas crianças do $2^{\circ}$ ano de escolaridade que participaram no Programa ao terem feito com que as suas mães participassem indirectamente no Programa, nomeadamente na ajuda que davam a escolher muitos dos materiais de leitura trazidos de casa para as sessões tutoriais, a parti- 
lha de informações e idéias que eram discutidas nas sessões de leitura poderão ter contribuído para uma maior aproximação mãe-criança. Estes comportamentos poderão ser responsáveis pelas mudanças significativas na percepção da relação que as crianças tinham com as suas mães, sendo esta mais positiva no final do Programa de Leitura a Par.

No que se refere aos alunos do $4^{\circ}$ ano, a influência do Programa de Leitura a Par foi mais positiva na Competência Escolar e Comportamento, tendo tido um efeito muito semelhante nas restantes dimensões. Estas crianças, que sentiam dificuldades na leitura, também se confrontavam, muitas delas, segundo a opinião dos seus professores, com dificuldades em todo o processo de aprendizagem. No momento da seleção dos participantes e durante a reunião que inicialmente tivemos com os seus professores, alguns destes alunos foram, ainda, apontados pelos seus professores como sendo crianças com comportamentos disruptivos, incomodando, frequentemente, o decorrer das aulas.

Como explicar então a evolução dos valores de autoconceito nestas crianças? Alguns destes alunos do $4^{\circ}$ ano que participaram no Programa de Leitura a Par, que experimentaram, muitas vezes, no seu percurso escolar o sentimento de fracasso interiorizando a imagem de mau aluno, conseguiram na relação tutorial superar esse sentimento, uma vez que sentiam convergir à sua volta o respeito e a admiração dos seus colegas. Dificilmente, nas suas salas de aula, estas crianças teriam a oportunidade de se colocarem numa situação de tutores, uma vez que eram percebidos como maus alunos, logo nunca poderiam ajudar uma outra criança em dificuldade.

Um outro aspecto que teria contribuído para a elevação dos valores de percepção de Competência Escolar terá sido as práticas avaliativas utilizadas. Na sala de aula, as crianças habitualmente tendem a comparar-se umas com as outras, até porque este processo é muito estimulado quer pelos professores quer pelos alunos. Estas crianças estavam em classes muito heterogêneas em termos de competências. As notas obtidas e os comentários sobre os seus desempenhos eram, muitas vezes, divulgados em voz alta pelos seus professores. Isto pode provocar nas crianças sentimentos de inferioridade em relação aos colegas. Para Lopes (2002) e Marsh e Craven (2006), esta comparação social influencia a percepção de competência.

No Programa de Leitura a Par tentou-se, sempre que possível, avaliar o esforço em relação aos progressos demonstrados pela criança no desempenho de uma tarefa. Tentou-se sempre colocar a ênfase nos progressos, o que contribuiu, de algum modo, para que estas crianças atribuíssem o seu desempenho ao esforço despendido. $\mathrm{O}$ reforço dado pelo colega era uma forma de feedback construtivo, contingente à qualidade do trabalho do tutorando e aos seus progressos. Deste modo, acreditamos que esta forma de avaliar os alunos foi muito importante não só para a sua motivação como poderá ter afectado de forma positiva a sua percepção de competência escolar.

Alguns destes alunos eram considerados pelos seus professores como mal comportados e que perturbavam o bom funcionamento das aulas. Verificou-se a este propósito que estas crianças ao longo do Programa de Leitura a Par demonstraram uma preocupação em controlarem o seu comportamento, de modo a que a relação entre os dois elementos da díade fosse a mais apropriada. Quanto aos tutores, pensamos que o fato de lhes ter sido atribuída uma grande responsabilidade, em termos de preparação das sessões tutoriais, na escolha das tarefas e das estratégias de leitura, contribuiu para um aumento de crenças positivas em relação ao seu comportamento e sobre o que os outros mais significativos pensavam deles a esse propósito. Um outro aspecto a considerar na explicação desta evolução prende-se com o objectivo que os tutores deveriam atingir durante as sessões tutoriais: ajudar um colega com dificuldades. A definição clara do objectivo e o esforço empreendido pelos tutores para o atingirem permitiu-lhes tomar decisões e avaliar as tarefas e os seus comportamentos de forma sistemática, ajudando-os a ter uma percepção mais positiva e real do seu comportamento.

Relativamente às dimensões do autoconceito que avaliavam a Competência Atlética e a Aparência Física, constatou-se que relativamente ao Grupo de Controle, as crianças do Grupo Experimental apresentaram valores superiores e significativamente diferentes, do ponto de vista estatístico. Quanto à Aceitação Social, e tal como estávamos à espera, as crianças que participaram no Programa de Leitura a Par sentiam-se mais populares, porque tinham mais amigos, sentiam que eram melhor compreendidas/integradas pelos colegas, do que as crianças do Grupo de Controle. Pensamos que o Programa de Leitura a Par, até pela interpretação que fizemos nas mudanças positivas observadas no autoconceito do Comportamento, terá influenciado o autoconceito da Aceitação Social, levando a que os alunos que nele participaram se sentissem melhor aceites pelos que os rodeiam adoptando comportamentos que os faziam sentir pertencer a um grupo. Harter (1982), nos seus estudos, afirma ter verificado uma correlação forte entre os valores da Aceitação Social e os valores da Competência Atlética e Aparência Física. Estes dados sugerem que as crianças que se vêem como melhor compreendidas/integradas pelos seus pares, também são as que se vêem como mais competentes em termos atléticos e mais atractivas fisicamente. Podemos, então, deduzir que estas crianças, que até à realização do Programa de Leitura a Par, se sentiam menos populares, com a sua participação no Programa passaram a sentir-se mais populares, sentindo convergir à sua volta mais pessoas, levando-as a sentirem-se mais atrativas fisicamente e mais competentes em termos atléticos.

Ao analisarmos os dados obtidos pelas crianças do $4^{\circ}$ ano na dimensão da Auto-Estima, constatamos que as 
crianças do Grupo Experimental evoluíram de forma significativa do pré para o pós-teste, apresentando valores significativamente superiores aos das crianças do Grupo de Controle. A Auto-Estima refere-se a uma visão global que a pessoa tem sobre si própria (Harter, 1993), baseada em processos de natureza afetiva. De acordo com esta autora (Harter, 1985) a percepção de competência nas diferentes dimensões correlaciona-se positivamente entre si e com a Auto-Estima, afirmando que estas correlações com a auto-estima são mais fortes com as dimensões da Aceitação Social e Aparência Física. No presente estudo os valores de autoconceito das crianças do Grupo Experimental aumentaram significativamente do pré para o pós-teste em todas as dimensões avaliadas logo, seria de esperar que estes apresentassem valores de Auto-Estima também mais elevados na situação de pós-teste. Para esta autora, as crianças que sentem que têm mais apoio social são também as que têm uma Auto-Estima mais elevada.

Os dados obtidos neste estudo permitem-nos afirmar que o Programa de Leitura a Par trouxe benefícios para as crianças que nele participaram, em termos de mudanças positivas no seu autoconceito e na sua auto-estima e provocou reações afetivas que influenciaram a motivação para a leitura. Na realidade, estas crianças mostraram-se muito motivadas para realizarem as inúmeras tarefas de leitura que foram escolhendo ao longo dos meses de participação no Programa. O perceber que tinham sucesso nessas tarefas e o reforço positivo que os tutorandos recebiam sistematicamente dos tutores levaram a que tutores e tutorandos passassem a ter uma percepção de competência mais positiva. As crianças, ao sentirem-se competentes, segundo Ryan e Deci (2000), envolvem-se mais em atividades desafiantes, sentem-se melhor e mostram menos ansiedade em relação aos resultados escolares, retirando um maior prazer intrínseco na realização das tarefas.

Estas estratégias proativas, nomeadamente o feedback construtivo, as oportunidades para participar em atividades com sucesso e para escolherem os materiais de leitura, e ainda o suporte fornecido pelos tutores e supervisor para que fizessem atribuições de sucesso e insucesso adequadas terão sido a chave principal para o sucesso da implementação deste Programa de Leitura a Par.

\section{Referências}

Alves-Martins, M., Mata, L., Monteiro, V., \& Peixoto, F. (1995). Escala de auto-conceito para crianças e pré adolescentes de Susan Harter. In L. S. Almeida, M. R. Simões, \& M. M. Gonçalves (Eds.), Provas psicológicas em Portugal (pp. 7989). Braga, Portugal: Associação dos Psicólogos Portugueses.

Carneiro, G., Martinelli, S., \& Sisto, F. (2003). Autoconceito e dificuldades de aprendizagem na escrita. Psicologia: Reflexão e Crítica, 16, 427-434.
Cubero, R., \& Moreno, M. C. (1995). Relações sociais nos anos escolares: Família, escola, companheiros. In C. Coll, J. Palacios, \& A. Marchesi (Eds.), Desenvolvimento psicológico e educação: Psicologia Evolutiva (pp. 250-260). Porto Alegre, RS: Artes Médicas.

Departamento da Educação Básica. (2000). Provas de aferição do Ensino Básico. Lisboa, Portugal: Autor.

Duran, D., \& Monereo, C. (2008). The impact of peer tutoring on the improvement of linguistic competence, self-concept as a writer and pedagogical satisfaction. School Psychology International, 29, 481-499.

Gambrell, L., \& Mazzoni, S. A. (1999). Principles of best practice: Finding the common ground. In L. B. Gambrell, L. M. Morrow, S. B. Neuman, \& M. Press Ley (Eds.), Best practices in literacy instruction (pp. 11-21). New York: Guilford Press.

Good, T., \& Brophy, J. (2002). Looking in classrooms. Boston: Allyn \& Bacon.

Harter, S. (1982). The perceived competence scale for children. Child Development, 53, 87-97.

Harter, S. (1985). Manual for the self-perception profile for children. Denver, CO: University of Denver.

Harter, S. (1993). Causes and consequences of low self-esteem in children and adolescents. In R. B. Baumeister (Ed.), Selfesteem - The puzzle of low self-regard (pp. 87-116). New York: Plenum Press.

Harter, S. (1996). Historical roots of contemporary issues involving self-concept. In B. Bracken (Ed.), Handbook of self-concept: Developmental, social and clinical considerations (pp. 1-37). New York: John Wiley \& Sons.

Harter, S. (1999). Construction of the self: A developmental perspective. New York: The Guilford Press.

Harter, S., \& Pike, R. (1983). The Pictorial scale of perceived competence and acceptence for young children. Denver, CO: University of Denver.

Inspecção Geral da Educação. (2001). Avaliação integrada das escolas: Relatório Nacional. Lisboa, Portugal: Autor.

Leung, C., Marsh, H. W., \& Craven, R. G. (2005). Are peer tutoring programs effective in promoting academic achievement and self-concept in educational settings: A mataanalytical review. Paper presented at the Conference of Australian Association of Research in Education, Melbourne, Australia.

Lopes, J. (2002). Problemas de comportamento, problemas de aprendizagem e problemas de "ensinagem". Coimbra, Portugal: Quarteto.

Marsh, H. W., \& Craven, R. G. (2006). Reciprocal effects of self-concept and performance from a multidimentional perspective: Beyond seductive pleasure and unidimensional. Perspectives on Psychological Science, 1, 133-163.

Marsh, H. W., \& Hattie, J. (1996). Theoretical perspectives on the structure of self-concept. In B. Bracken (Ed.), Handbook of self-concept: Developmental, social and clinical considerations (pp. 91-170). New York: John Wiley \& Sons.

Marsh, H. W., \& O’Mara, A. J. (2008). Self-concept is as multidisciplinary as it is multidimensional: A review of theory, measurement, and practice in self-concept research. In H. W. Marsh, R. G. Craven, \& D. M. McInerney (Eds.), Self-processes, learning, and enabling human potential: Dynamic new approaches (Vol. 3, pp. 87-118). Charlotte, NC: Information Age. 
Marsh, H. W., \& Shavelson, R. J. (1985). Self-concept: Its multifaceted, hierarchical structure. Educational Psychologist, 20, 107-125.

Mata, L., Monteiro, V., Peixoto, F., \& Alves-Martins, M. (1998). Adaptação da Pictorial Scale of Perceived Competence and Social Acceptance for Young Children de Harter \& Pike. Lisboa, Portugal: Instituto Superior de Psicologia Aplicada.

Maroco, J. (2007). Análise estatística com utilização do SPSS. Lisboa, Portugal: Sílabo.

Miller, D., \& Moran, T. (2006). Positive self-worth is not enough: Some implications of a two-dimensional model of self-esteem for primary teaching. Improving Schools, 9, 7-16.

Monteiro, V. (2003). Leitura a par: Efeitos de um programa tutorial no desempenho em leitura, motivação, autoconceito e auto-estima, de alunos do $2^{\circ}$ e $4^{\circ}$ anos de escolaridade. (Tese de Doutorado não-publicada). Faculdade de Ciências, Departamento de Educação, Universidade de Lisboa, Portugal.

Pinto-Ferreira, C., Serrão, A., \& Padinha, L. (2007). PISA, 2006Competencias científicas dos alunos portugueses. Lisboa, Portugal: Ministério da Educação.

Rohrbeck, C., Ginsburg-Block, M., Fantuzzo, J., \& Miller, T. (2003). Peer-assisted learning interventions with elementary school students: A meta-analytic review. Journal of Educational Psychology, 95, 240-257.

Rumbaugh, W., \& Brown, C. (2000). The impact of reading recovery participation on student's self concepts. Reading Psychology, 21, 13-18.

Ryan, R., \& Deci, E. (2000). Intrinsic and extrinsic motivations: Classic definition and new directions. Contemporary Educational Psychology, 25, 54-67.

Sim-Sim, I. (2001). Um retrato da situação: Os dados e os factos. In I. Sim-Sim (Ed.), A formação para o ensino da língua portuguesa na educação pré-escolar e no $1^{\circ}$ ciclo do ensino básico (pp. 11-26). Porto, Portugal: Porto Editora.

Topping, K., \& Brice, A. (2004). Cross-age peer tutoring of reading and thinking: Infuence on thinking skills. Educational Psychology, 24, 595-621.

Veerkamp, M., \& Kamps, D. (2007). The effects of classwide peer tutoring on the reading achievement of urban middle school students. Education and Treatment of Children, 30, 21-51.

Wigfield, A., \& Karpathian, M. (1991). Who am I and what can I do? Children's self-concept and motivation in achievement situations. Educational Psychologist, 26, 233-261. 